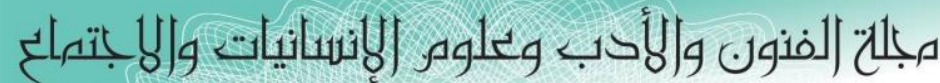

Journal of Arts, Literature, Humanities and Social Sciences

ISSN online: 2414 - 3383

ISSN print: 2616 - 3810

العدد (41) آب - أغسطس 2019

\title{
المردود الاقتصادي السياحي لضم الاهوار للائحة التراث العالمي
}

\author{
م.م. بسام عبد الباري هندي الخزاعي

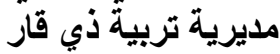

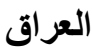

المخدم

تعد الاهو ار من اهم المصادر للتنمية الاقتصادية في جنوب العراق وخاصة بعد انضمامها الى لائحة التراث

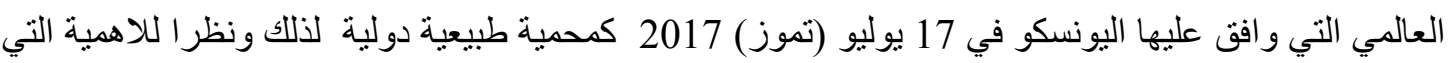
تتمتع بها هذة المنطقة سوف تكون موضوع البحث حيث سنتطرق الى مقومات التنمية في هذة المناطق و العناصر التي تتوفر فيها وقد تم اختيار هور الجبايش كنموذج للاهو ار وسوف يكون مكان الدراسة ـ اذ نقسم هذا البحث الى ثلاث مباحث ضم المبحث الاول توضيح لمفهوم التتمية الاقتصادية ودور ها في رفع المستوى المعاثشي للافر اد وكذالك ضم عناصر ومقومات التتمية الاقتصادية وما هو موجود من هذة المقومات في الاهوار والذي سوف يساهم في تطويرها وارتقاءها اما المبحث الثاني فضم التركيز على دور السياحة في التنمية الاقتصادية وتركز الموضوع حول دور ها في اهو ار الجبايش لما حدث فيها من تغير ات بعد انضمامها الى لائحة التراث العالمي وخاصة ارتفاع اعداد السواح فيها بحسب ما ذكرته الجرائد الرسمية للمنطقة وحسب ماذكر الاستاذ جاسم الاسدي اما المبحث الثالث فقد ضم بعض المقترحات لتطوير السياحة في المنطقة لجعلها قبلة

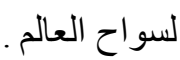


مبلحت (لفنون والأدب وعلوه الإنسانيات والبانتهاع

Journal of Arts, Literature, Humanities and Social Sciences

ISSN online: 2414 - 3383

ISSN print: 2616 - 3810

العدد (41) آب - أغلسطس 2019

\section{The Economic Return of Tourism to Include the Marshes into the List of World Heritage}

\section{ABSTRACT}

The Marshlands are one of the most important sources of economic development in southern Iraq, especially after its accession to the World Heritage List, which was approved by UNESCO on 17 July 2017 as an international natural reserve. The importance of this region will be the subject of research. Areas and elements that have been selected Hor Chibayish has been selected as a model of the marshes and will be the place of study. . As we divide this research into three sections included first topic to clarify the concept of economic development and its role in raising the living standards of individuals, and also included elements of the elements of economic development, and what is the present of these ingredients in the marshes, which will contribute to the development and upgrading its either second section annexation focus on the role of tourism in development economic focus on its role in the topic marshes Chibayish what happened to the changes after its accession to the World Heritage list, especially tourists high number of prepare them according to the official Newspapers according to professor Jassim al-Asadi tower, while the third section included some of Proposals for the development of tourism in the region to make them front the world for tourists. 


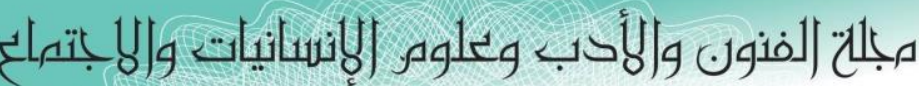

Journal of Arts, Literature, Humanities and Social Sciences

ISSN online: 2414 - 3383

ISSN print: 2616 - 3810

\section{العدد (41) آب - أغسطس 2019}

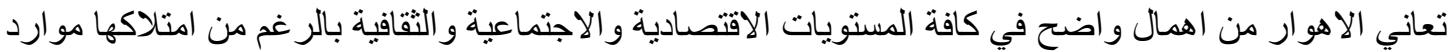

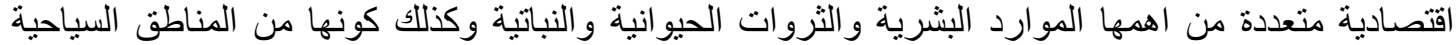

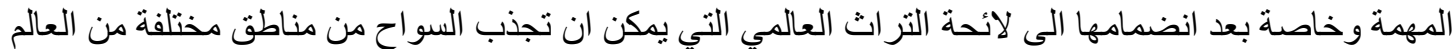

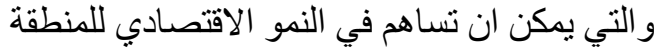

\section{فرضية البحث}

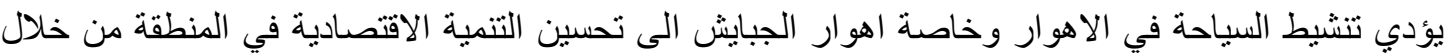

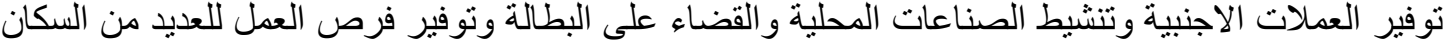

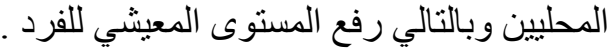
اهداف البحث 1- توضيح مفهوم التنمية الاقتصادية وتحديد عناصر ها ومقوماتها .

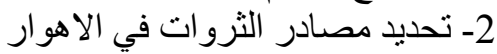
3- توضيح مدى تاثير السياحة على التنمية الاقتصادية للمنطقة

اعتمد البحث على المنهج الميداني في جمع البيانات و المقابلات الثخصية و الرجوع الى بعض بعض المصادر العلمية

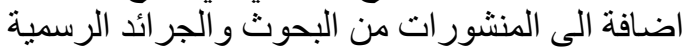

حود البحث البث

اهو ار الجبايش هي مجموعة من الاهوار في العراق شرق الناصرية تعتبر امتدادا لهور ابو زرك وهو الهو الحمار

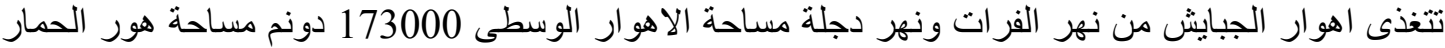

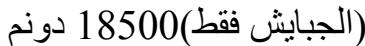

و الجبايش جمع كلمة جبيشة التي هي جزيرة صناعية تسبح على سطح ماء الهور تم التحضير لها بعناية وكونت

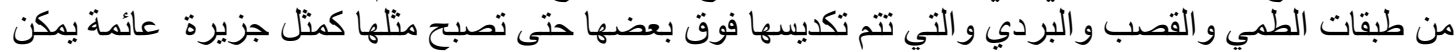

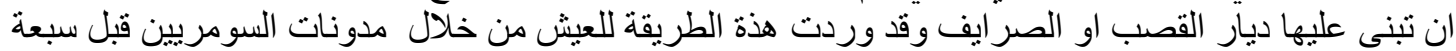

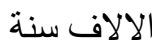

\section{المبحث الاول \\ ماذا نعني بالتنمية الاقثمادية}

ان اقتصاد اي دولة هو عنوان امن ونجاح هذة الدولة واكثر ما تهتم به القوى الاقتصادية في الدول المتقدمة هو الإدي

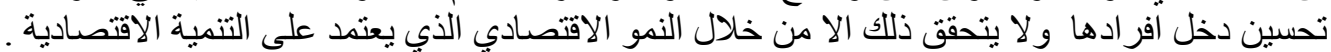

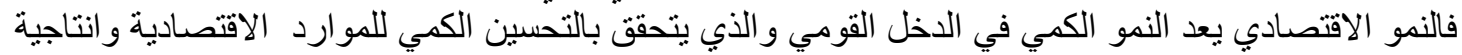

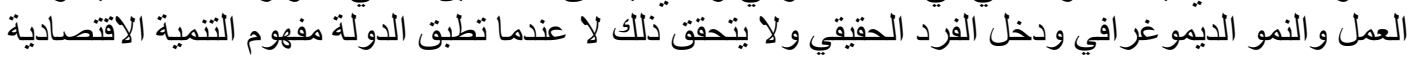

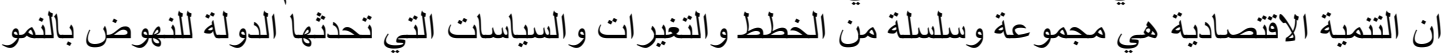

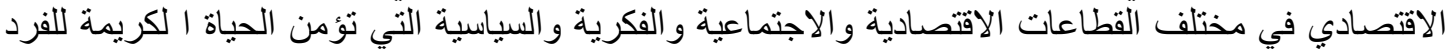
وتحسين مستوى دخله وتضمن استمر ارية النمو الاقتصادية الإنهاعية مقومات التنمية الاقتصادية التخية

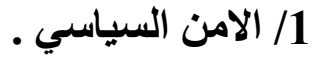

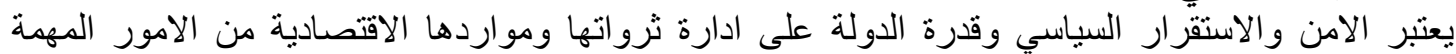

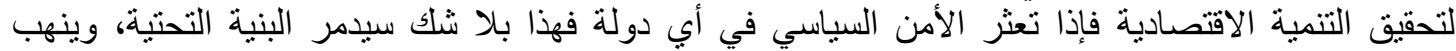
المنشآت الصناعية، ويسبب تفشي الفقر والبطالة، والكثير من المشاكل الاقتصاديّة الأخرى، كما يؤثر التنظيم 
مبلحت (لفنون والأدب وتلوه الإنسانيات والبنتهماع Journal of Arts, Literature, Humanities and Social Sciences

ISSN online: 2414 - 3383

ISSN print: 2616 - 3810

\section{العدد (41) آب - أغسطس 2019}

السياسي الذي يميل للمصلحة العامة في المحافظة على سير عجلة التّمية الاقتصادي، أي أنّ النظام السياسي

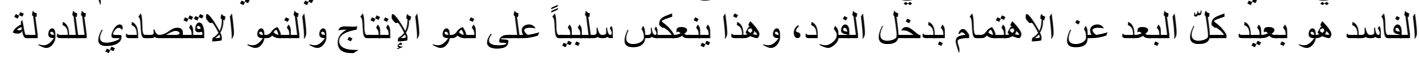

2 التعليم 2

يعتبر التعليم وتقدمة حاجة ملحة في التنمية الاقتصادية فالاهيت هتمام بالتعليم واحداث تنغييرات في النظام التعليمي

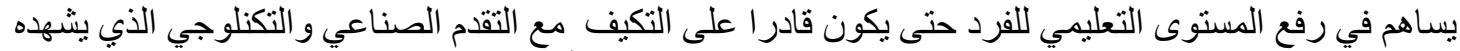

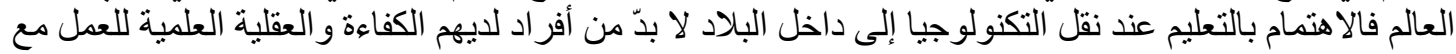

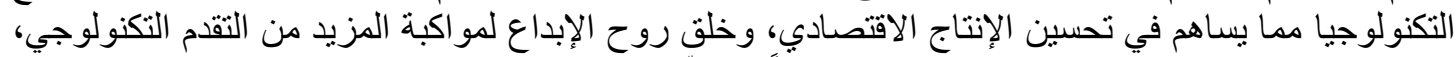

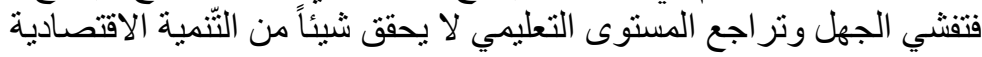

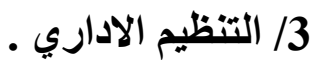

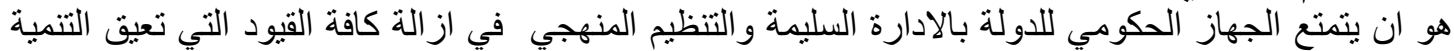

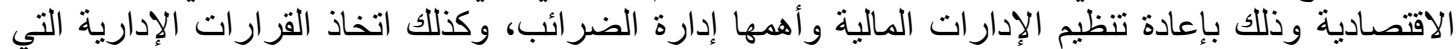

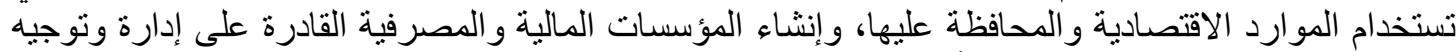

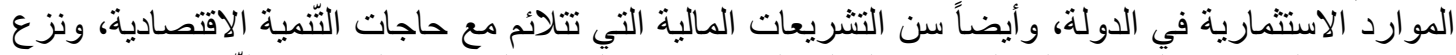

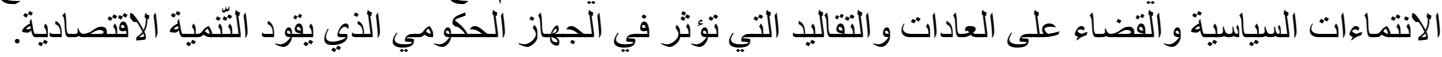

\section{عناصر التنمية الاقتصادية

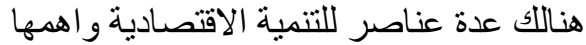

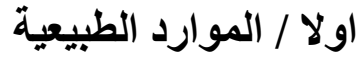 \\ ثانيا / الموارد / الموارد الطشية المية المودية \\ ثُالثًا / الموارد الموارد المصنعة}

الموارد الطبيعية

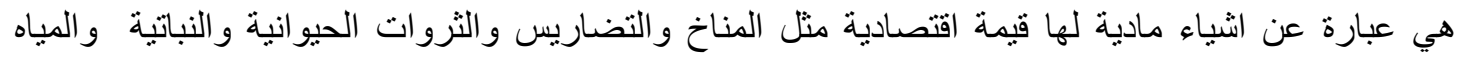

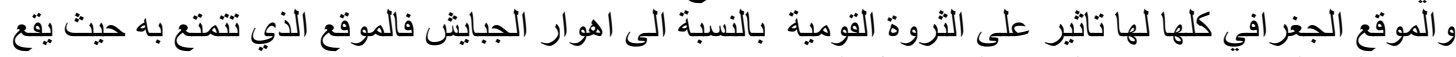

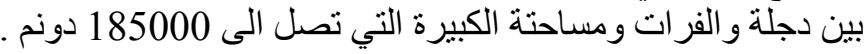

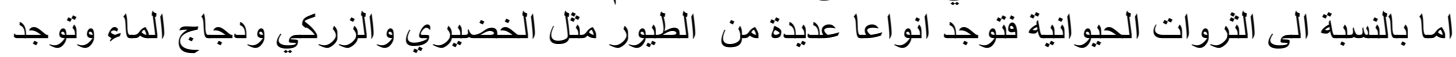

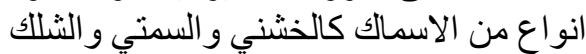
حيث توفر الاسماك الدخل الكافي لثريحة كبيرة من الصبادين تتر اوح بين (1000 - 1500) صياد مجاز رسميا منهم

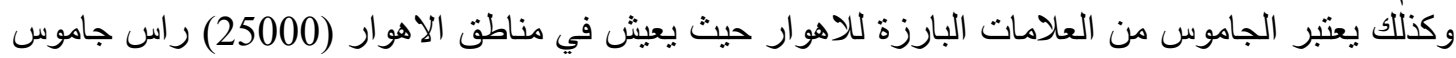

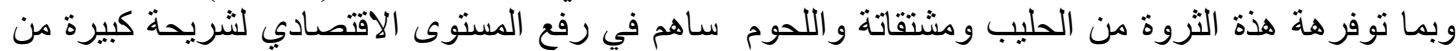

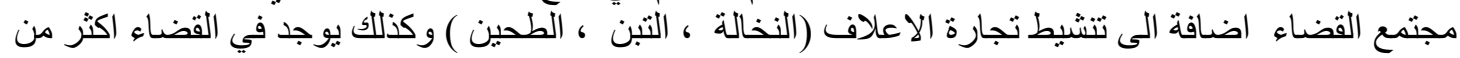

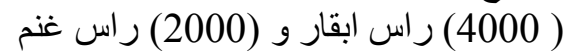
اما بالنسبة الى الثروات النبار واتية وتوجد النباتات المائية مثل القصب و البردي و الجو لان و غيرها

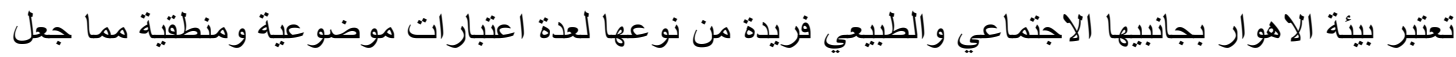

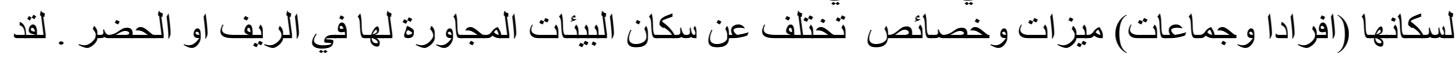




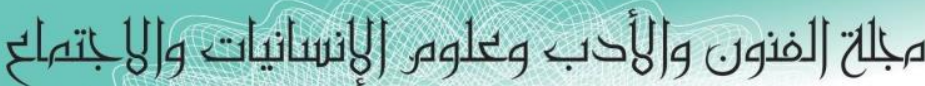

Journal of Arts, Literature, Humanities and Social Sciences

ISSN online: 2414 - 3383

ISSN print: 2616 - 3810

العدد (41) آب - أغسطس 2019

LALHSS

wWw.jalhss.com

ساهمت تللك البيئة الفريدة في بلورة ثقافات خاصة بها وهي عبارة عن عادات وتقاليد ونسق حياتي مختلف لم بتغير فترة طويلة

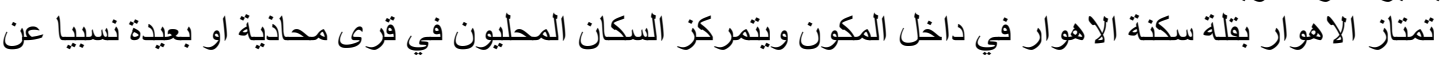

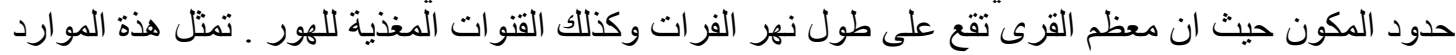

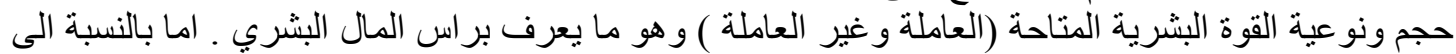

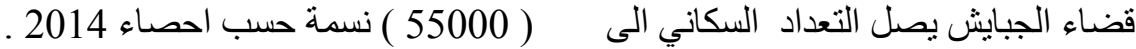

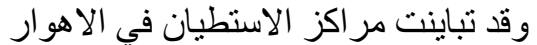

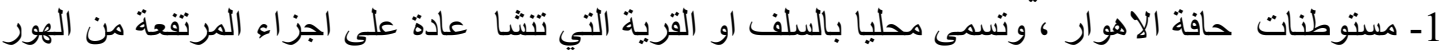

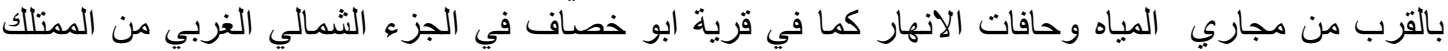

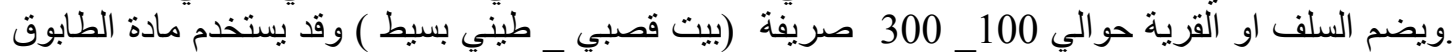
كمادة للبناء

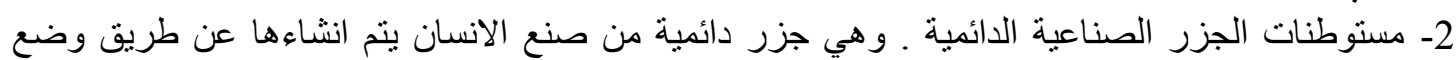

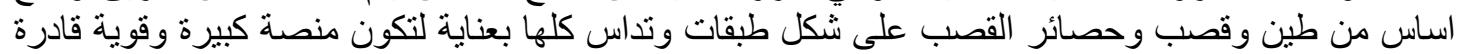
على تحمل الصريفة او المواشئ وائي

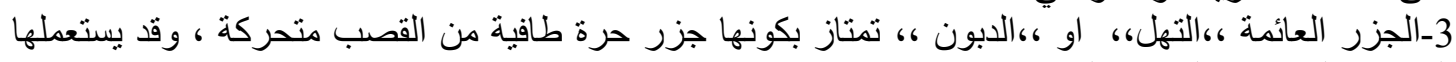

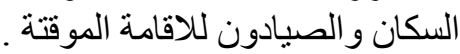

\section{المواد المصنعة} يعتمد سكان الاهو ار بنسبة عالية من معيشتهم على عدد من الانشطة الاقتصادية الاساسية المتنو عة و التتي تتميز

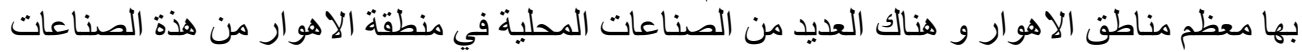

1

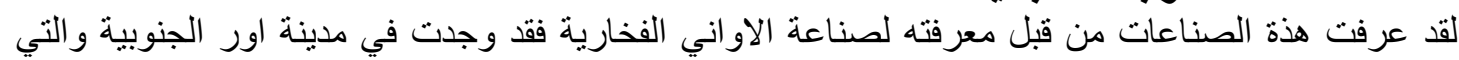

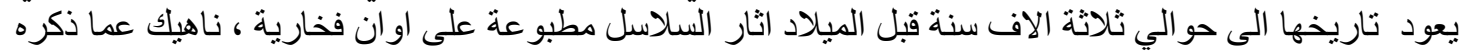

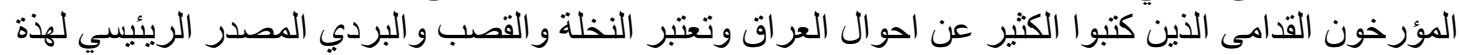

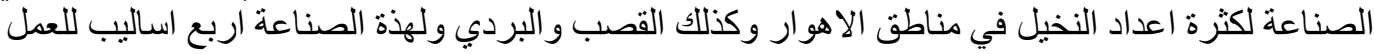

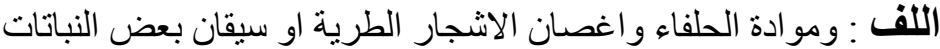

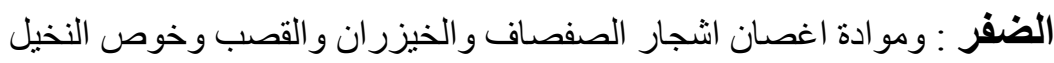

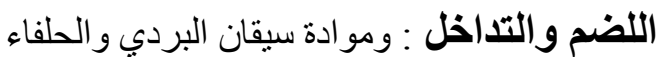

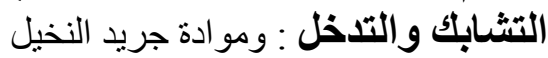

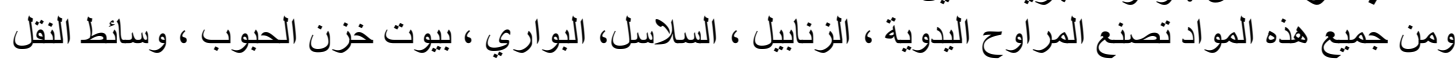

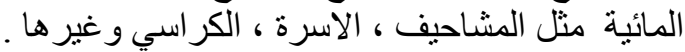

\section{2 - 2 - 2 الصناعات الخشبية}

حرفة قديمة ظهرت الحاجة اليها عندما وجد الانسان ضروبات ضرورة ملحة لاستقراره فتطلب حياته الجديدة ان ييني

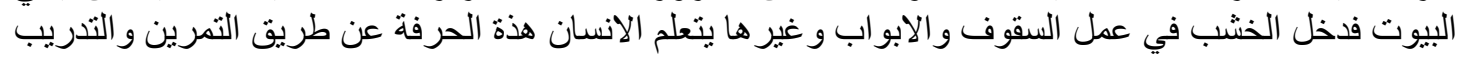

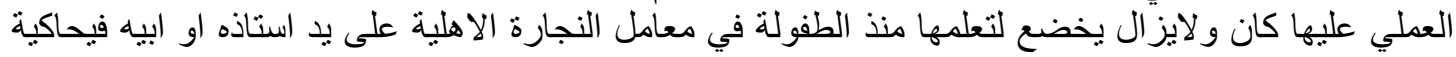

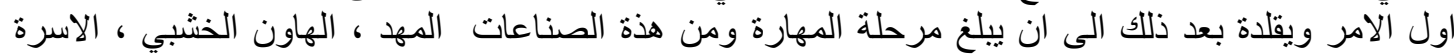
،الكر اسي ، الملاعق ، ادو ات الزينة مثل المشط الخشبي ، المحمل ، ومن الادوات المدة الموسيقية مثل الناي ، الطبلة ، 


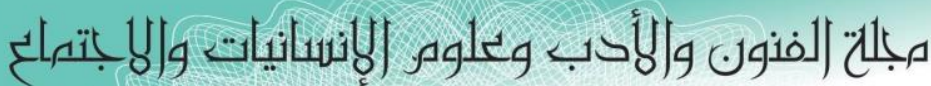

Journal of Arts, Literature, Humanities and Social Sciences

ISSN online: 2414 - 3383

ISSN print: 2616 - 3810

\section{العدد (41) آب - أغسطس 2019}

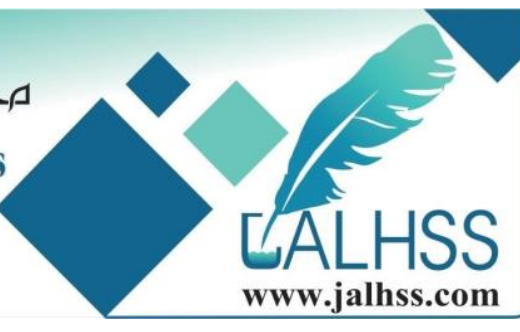

3 - الصناعات الحديدية

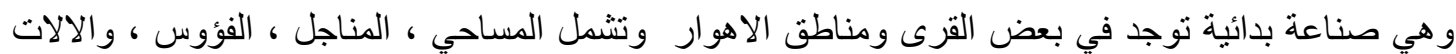

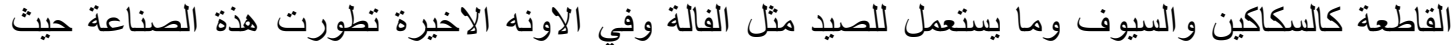

شملت صناعة الابو اب و الثبابيك وغير ها ولنيا.

\section{4 - 2 - الصناعات الغذائية}

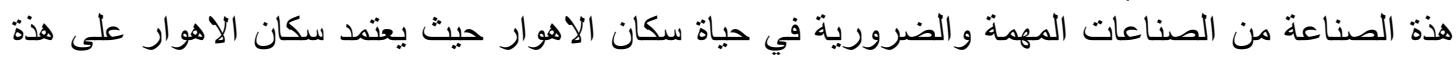

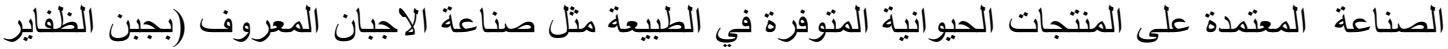

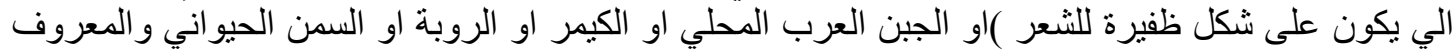
باسم ( دهن الحر ) او من المنتجات النباتية مثل الخريط المصنوع من حبوب اللقاح لنبات البردي الحير النيا

\section{دور السياحة في النمو الاقتصنادي في الاهوار}

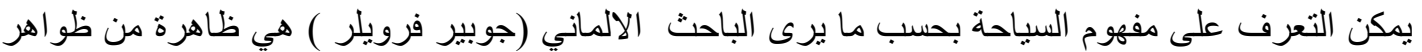

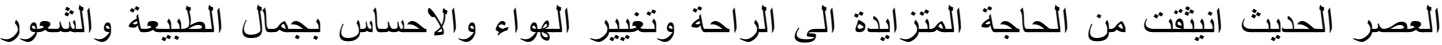

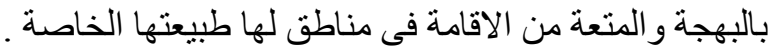
و السياحة صناعة تعتمد على حركة السكان السياحية ولمدة معينة من منطقة الىى اخرى داخل الدولة او من دولة

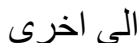
و هناللك عدة انواع للسياحة منها الدينية و العلاجية و الترفيهية و الاعمال و البيئية

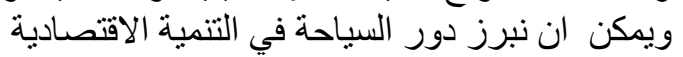

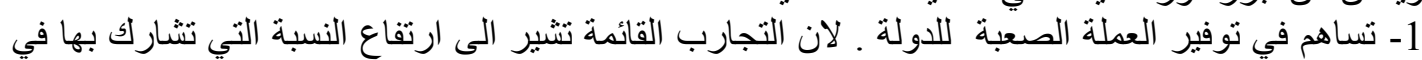
تكوين اير ادات الدول من العملة الصعبة الصناء

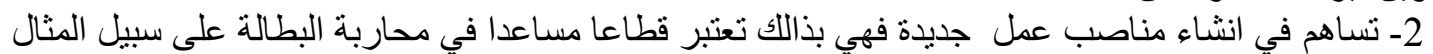

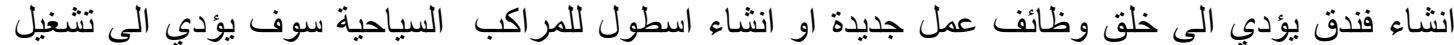
العديد من العاطلين عن العمل من غير لقائ حاملي الثهادات

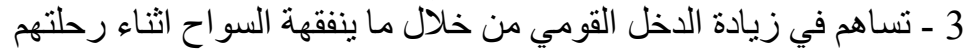

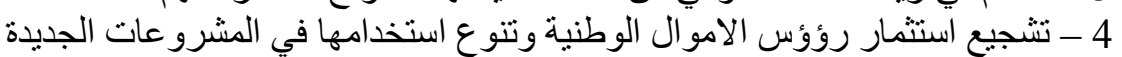

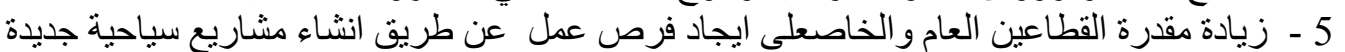
6- الاستغلال الامثل للموارد الطبيعية والاقتصادية وايجاد العاد استخدامات جديدة لها لهائ

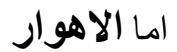

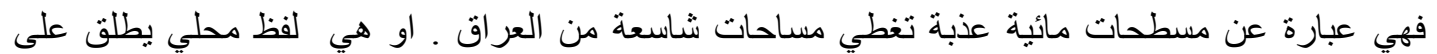

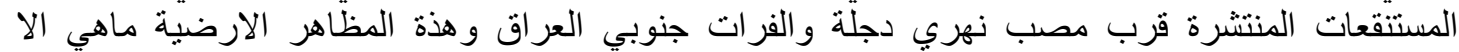

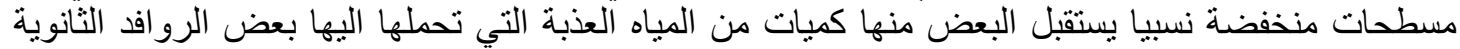

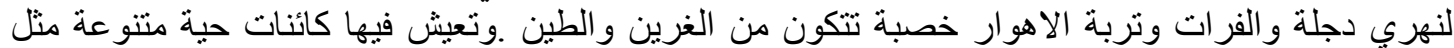

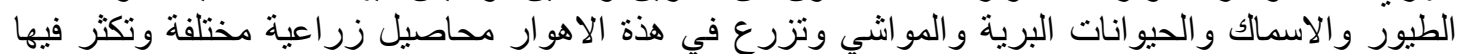

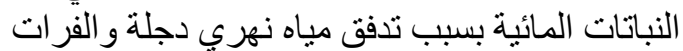

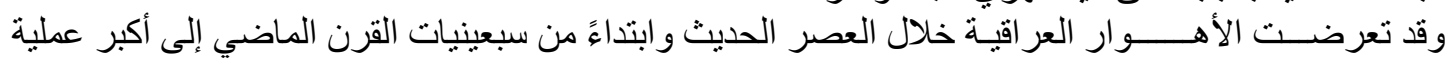
تجفيف وتدمير بيئي شهــده التاريخ لعدة أسباب منها اقتصادية مثل استخر اج النفط ومنها سياسية وعسكرية 


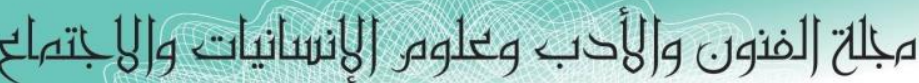

Journal of Arts, Literature, Humanities and Social Sciences

ISSN online: 2414 - 3383

ISSN print: 2616 - 3810

\section{العدد (41) آب-أغسطس 2019}

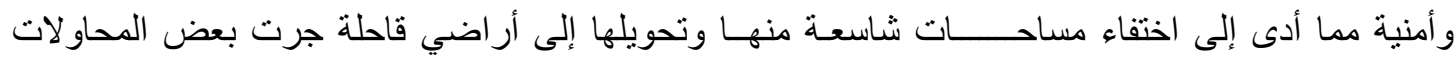
الفاثلة لاستصلاحها ولم يبقى من الأهو ار في عسام 2002 سوى 10\% و من المساحة الكلية للأهو ار الدائمية لعام 1973 و البالغة 8350 كم 2

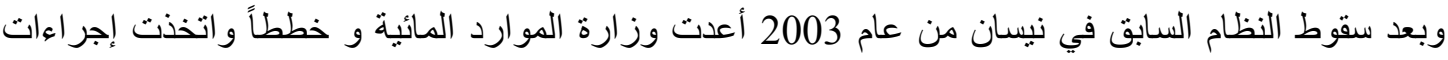

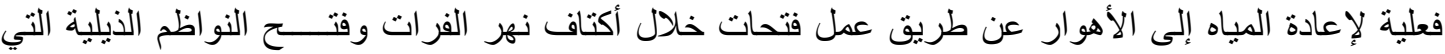

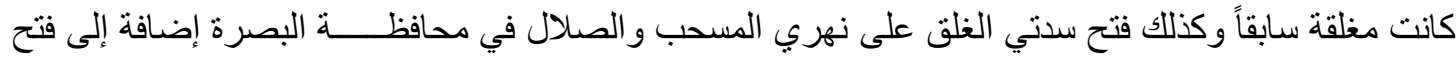

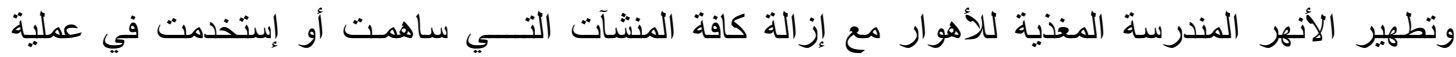

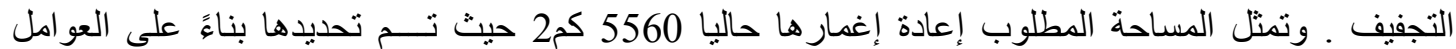

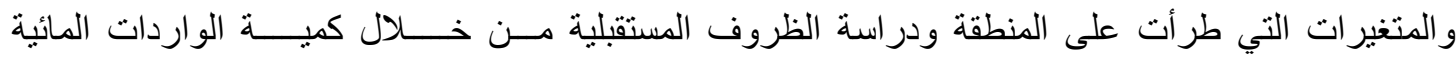
لنهري دجلة والفرات و غير ها من العو امل فيما تم استبعاد المساحة المتبقية من الاغمار .

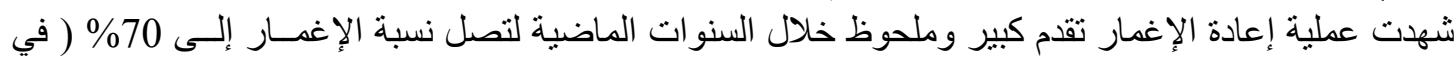
عام 2007 ) .

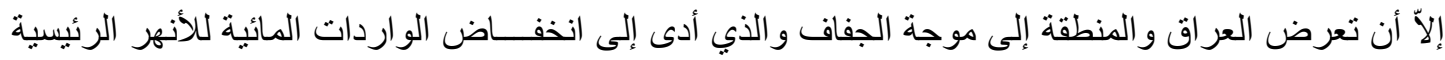

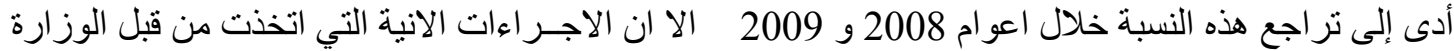

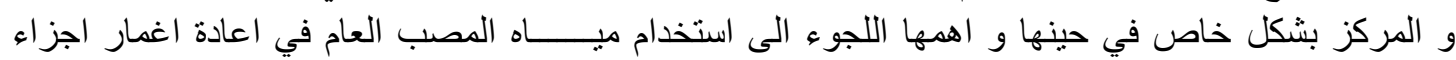

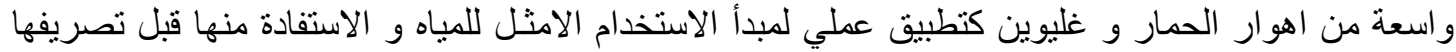

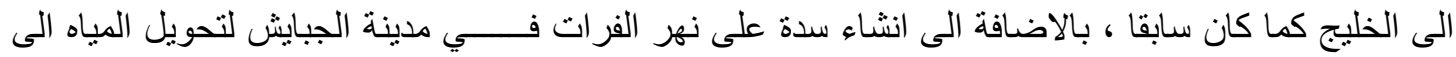

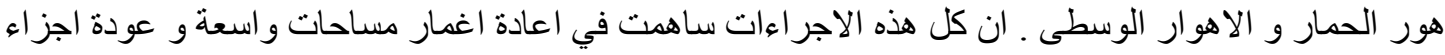

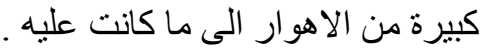


مبلحت (لفنون والأدب وعلوه الإنسانيات والهبتهماع Journal of Arts, Literature, Humanities and Social Sciences

ISSN online: 2414 - 3383

ISSN print: 2616 - 3810

\section{العدد (41) آب - أغسطس 2019}

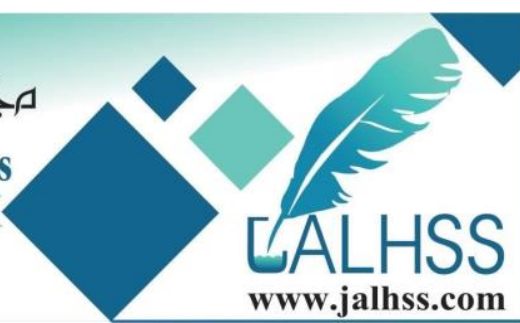

\section{عوامل نجاح السياحة في الاهوار}

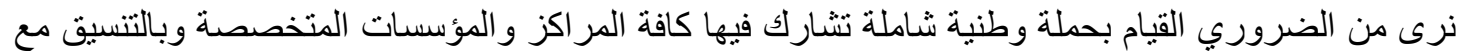

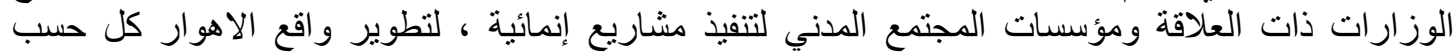

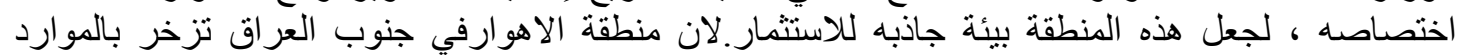

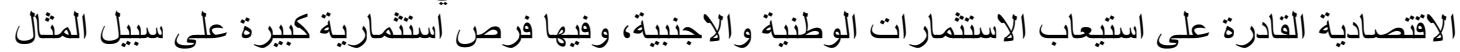

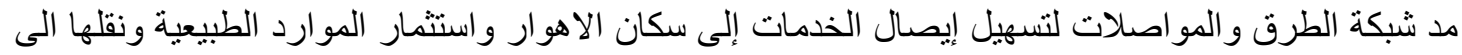

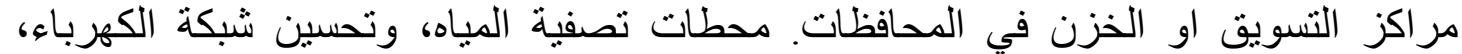

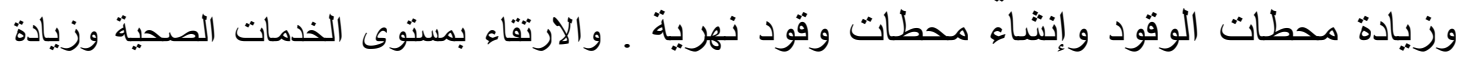

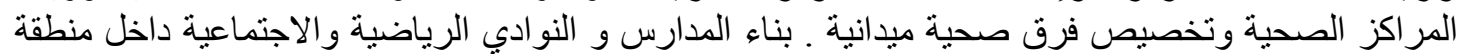

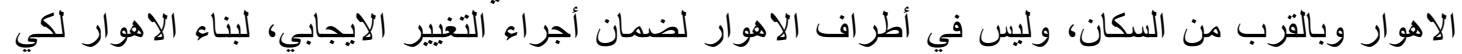

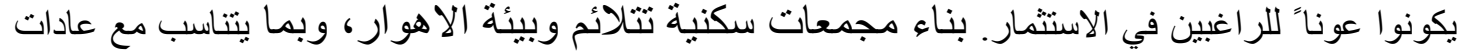

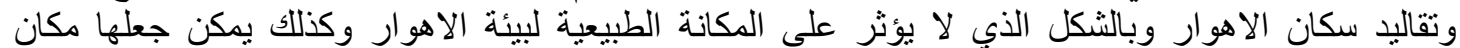

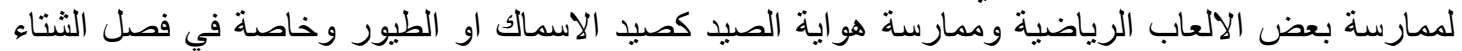

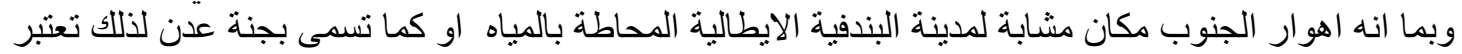

\begin{tabular}{|c|c|c|c|c|c|}
\hline \multicolumn{6}{|c|}{ جدول لنسب الإغمار للسنوات 2011 - 2014 سم } \\
\hline 2014 & 2013 & 2012 & 2011 & 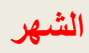 & التسلسل \\
\hline 67 & 61 & 46 & 47 & 1 & 1 \\
\hline 69 & 65.7 & 50 & 49 & 2 & 2 \\
\hline 72 & 66 & 53 & 49 & 3 & 3 \\
\hline 71 & 65 & 47 & 47 & 4 & 4 \\
\hline 66 & 67 & 46.7 & 47 & 5 & 5 \\
\hline 65 & 61.7 & 44 & 47 & 6 & 6 \\
\hline 62.6 & 63 & 42.9 & 49 & 7 & 7 \\
\hline 61 & 61 & 42 & 45 & 8 & 8 \\
\hline 60 & 58 & 41.3 & 44 & 9 & 9 \\
\hline 59 & 55.9 & 40.6 & 42 & 10 & 10 \\
\hline 59 & 60 & 40.9 & 43 & 11 & 11 \\
\hline 60 & 64 & 48 & 45 & 12 & 12 \\
\hline
\end{tabular}

مناطف سياحية جميلة .

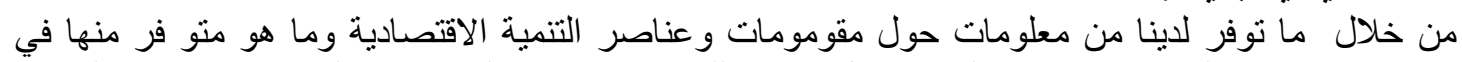

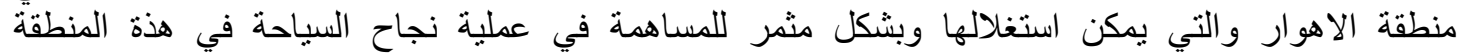

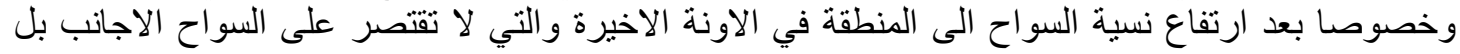




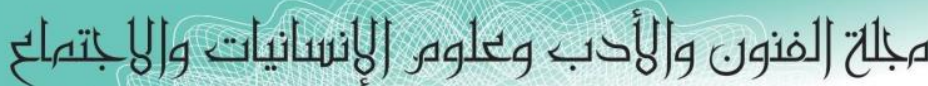

Journal of Arts, Literature, Humanities and Social Sciences

ISSN online: 2414 - 3383

ISSN print: 2616 - 3810

العدد (41) آب - أغسطس 2019

حتى العراقيين من كافة انحاء العراق ولكي تكون هذة المنطقة قبلة للترفية و التسلية والر احة النفسية للسواح التهاح

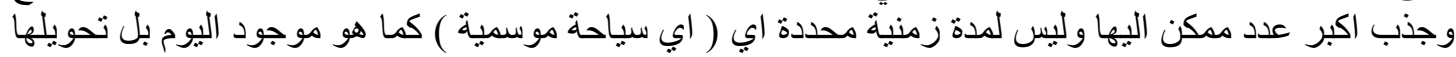

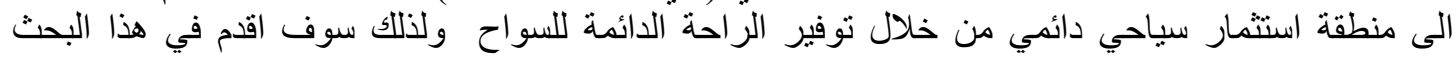

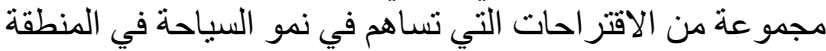

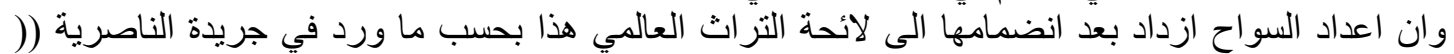

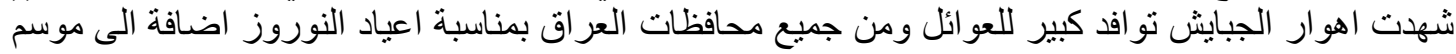

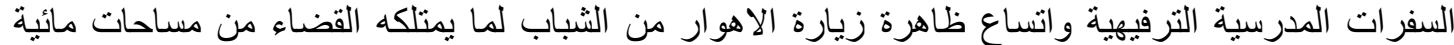

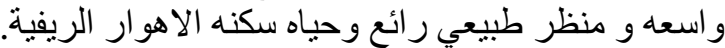

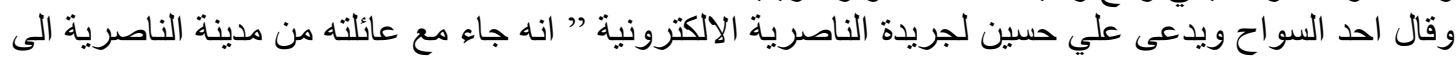

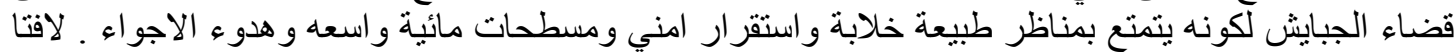

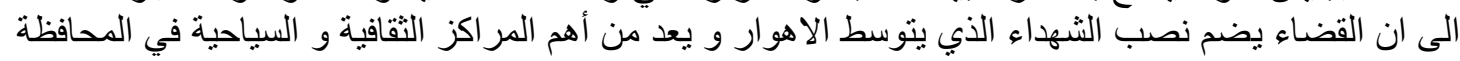

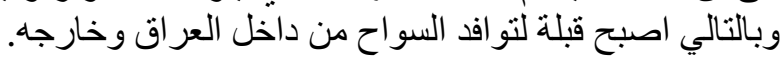

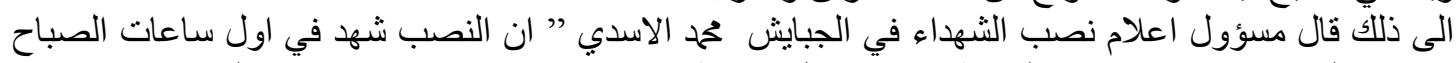

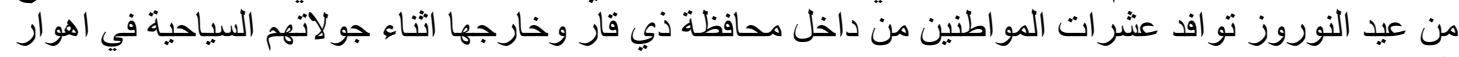

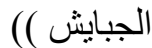

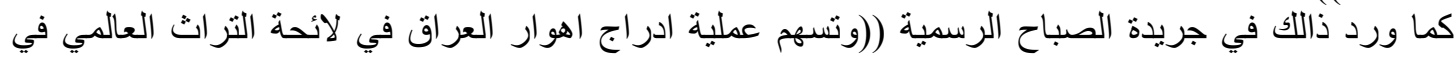

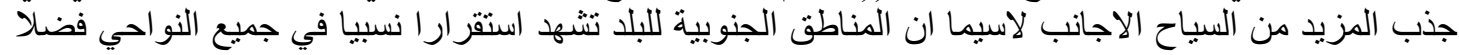

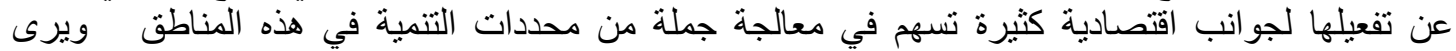

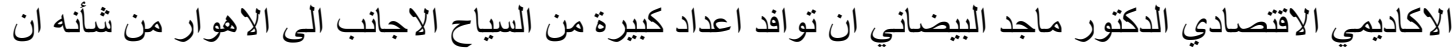

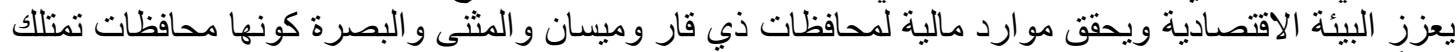

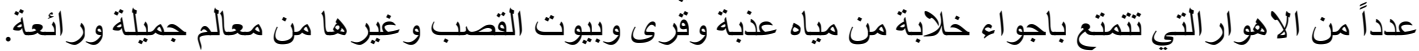

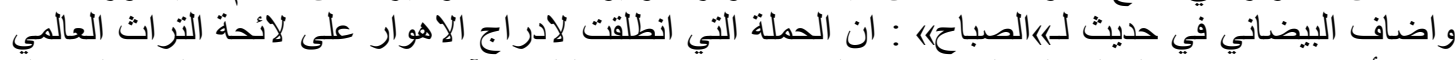

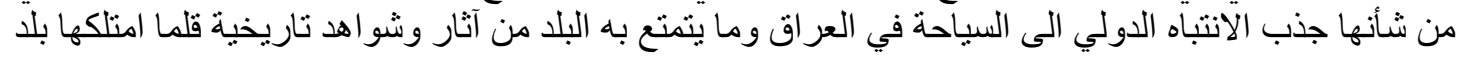
آخر. ودعا الى ايلاء القطاع السياحي مزيدا من الدعم لاسيما في ظل المرحلة الراهنة والظروف التي يشهدها العراق

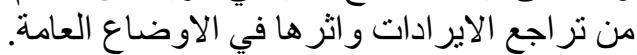

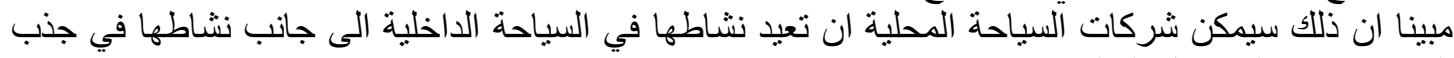

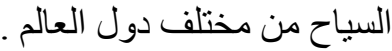

\section{المبحث الثالث \\ بعض المقتراحات لتطوير السياحة في الاهوار}

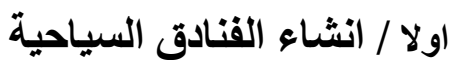

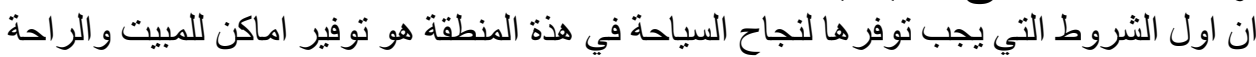

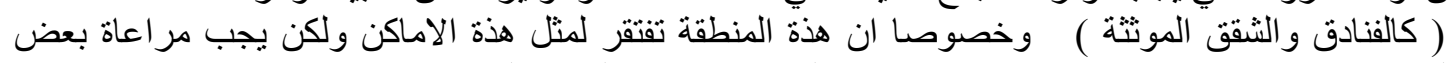

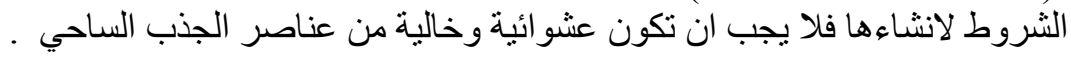

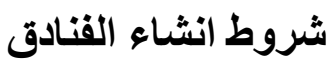

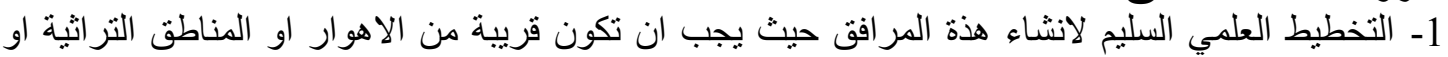

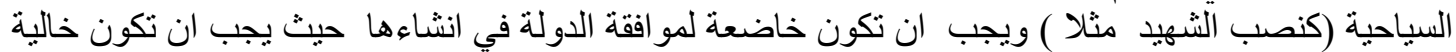
من العشو ائبة ويجب ان لا تتضارب مع خدمات اخرى موجودة في المنطقة 


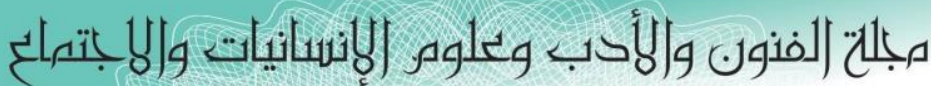

Journal of Arts, Literature, Humanities and Social Sciences

ISSN online: 2414 - 3383

ISSN print: 2616 - 3810

العدد (41) آب - أغسطس 2019

2- الاستغلال الامثل للموارد الطبيعية والبشرية

فعلى سبيل المثال عند انشاء فندق يجب ان يكون انعكاس لما هو متوفر في الطبيعة مثنا انشاء حجرات من

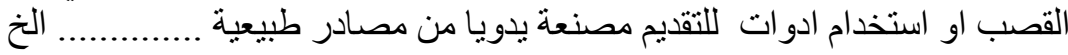

3- يجب وضع الثروط في انشاء الفنادق للمحافظة على البيئة فهي المورد الاساسي للجذ ب الساحي.

ثانيا / توفير المطاعم

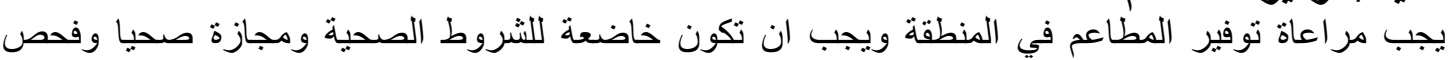

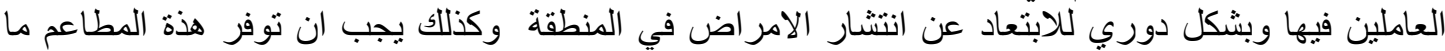
يطمح السائح لايجاده فيها كتوفير الاكلات الثعبية وخاصة ما هومشهور في هذة المنطقة وهي الاسماك و والخبز

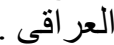

\section{تثالثا / تطوير اماكن الجذب السياحي}

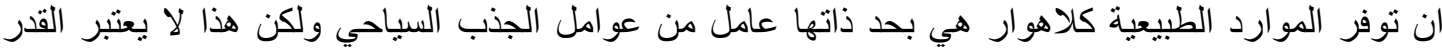

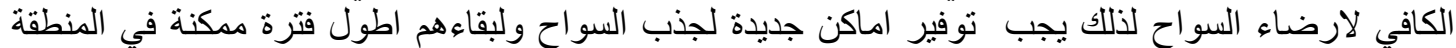

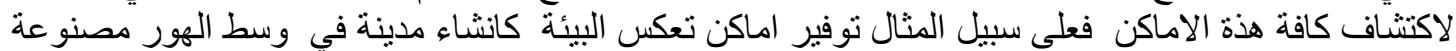

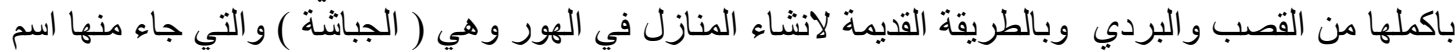

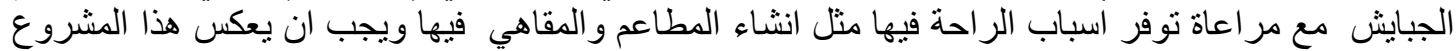

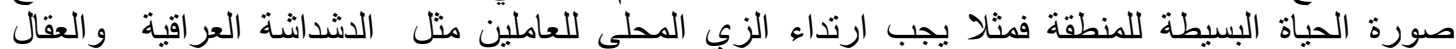

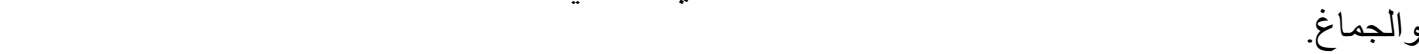
بالاضافة الى ذالك يجب مر اعاة الاماكن الاثرية وتطوير ها وتوفير كادر متخصص للعناية بها وارشاد السواح لاماكن تو اجدها

رابعا/ العمل على رفع كفاعة العنصر البشري

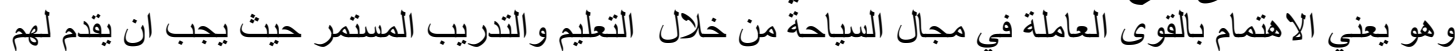

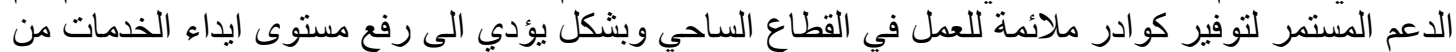

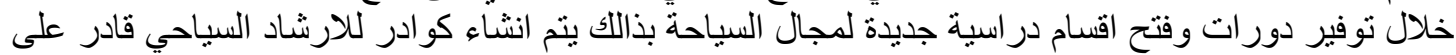
التعامل مع ازدياد متطلبات السياحة

خامسا / وضع خطط ترفيهية للسواح حيث يكون للاعلام الدور الامثل لنجاح هذة السياحة من خلال الملصقات والاعلانات وتوفير كراس وكتب

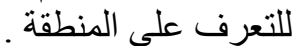
ويتم الترفيه السو المن من خلال

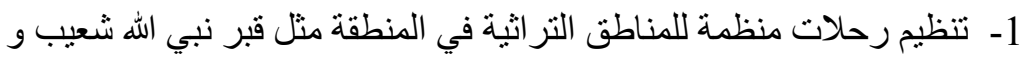

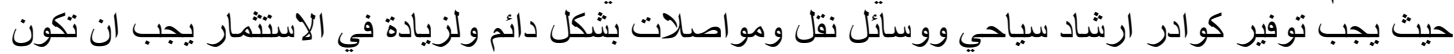
هذة الوسائل تابعة لهيئة السياحة في المنطقة 


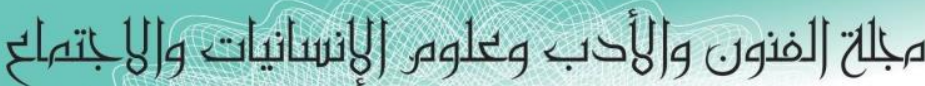

Journal of Arts, Literature, Humanities and Social Sciences

ISSN online: 2414 - 3383

ISSN print: 2616 - 3810

\section{العدد (41) آب - أغسطس 2019}

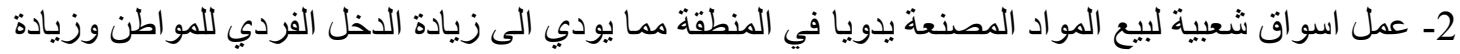

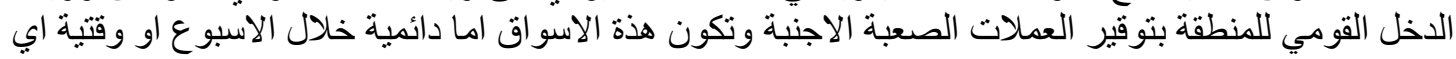

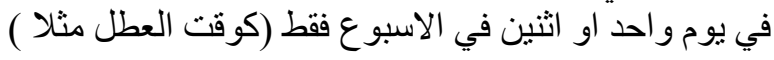

3- تهيئة مجمو عة من الزوارق للترفيه من خلال تنظيم رحلات الى اعماق الاهوار مع تامين اسس السلامة فيها .

الاستنتاجات

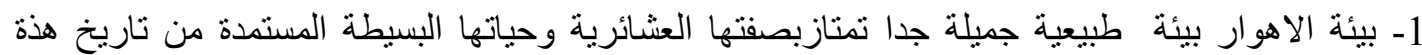

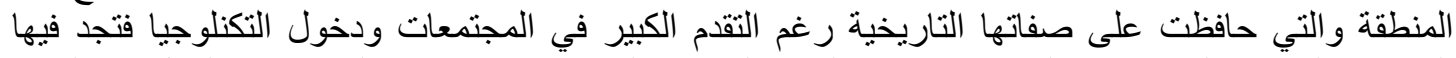

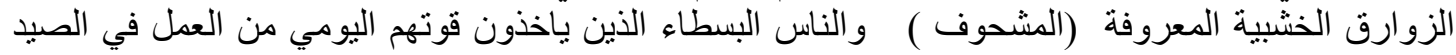

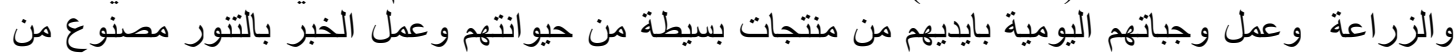

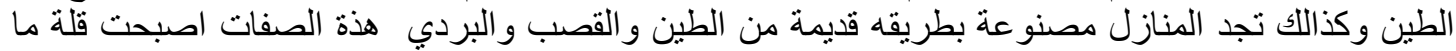

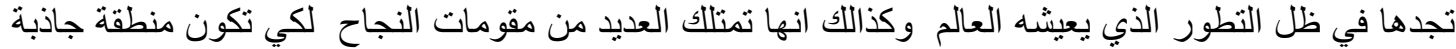
للسواح وتحقيق اعلى مستويات التنمية الاقتصادية لكي تعمل على رفع مستوى دخل الفردو واقضاء على النى البطالة ورفع مستوى التعليم

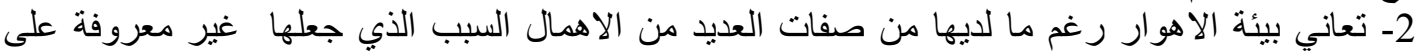

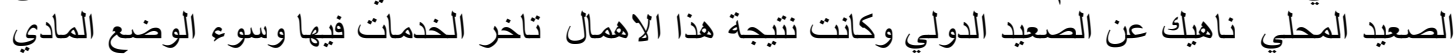
لافر ادها

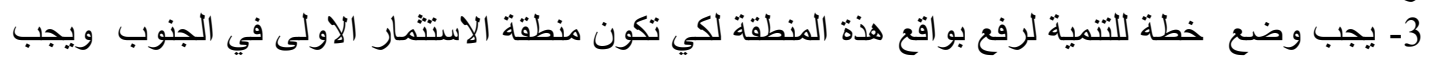

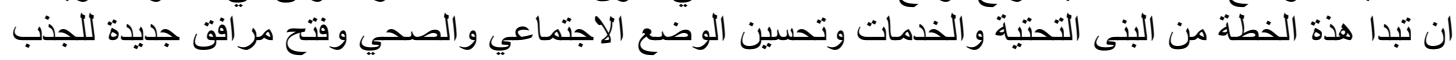
السياحي لكي تكون السياحة المصدر الاساسي للاخل كما رفع بديع ال خيون شعار السياحة نفط متجدي

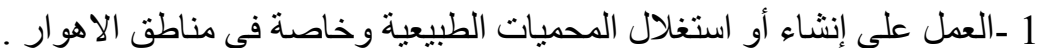

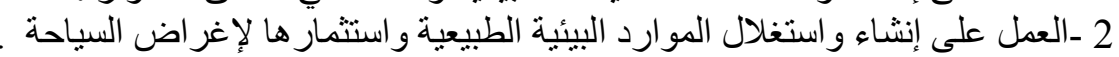

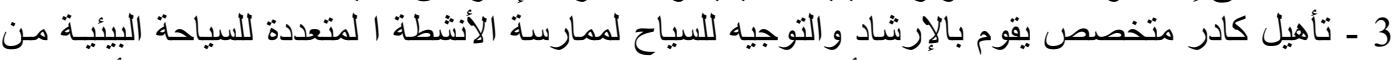

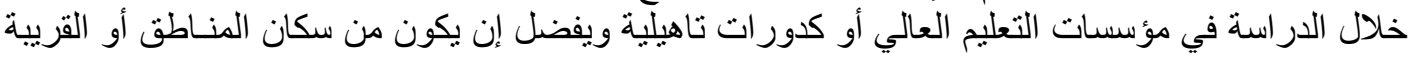

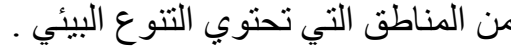

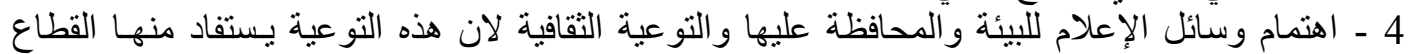

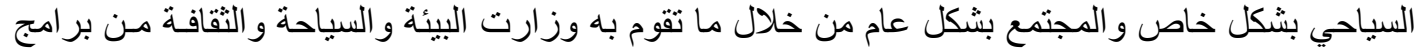

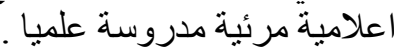

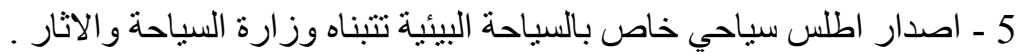

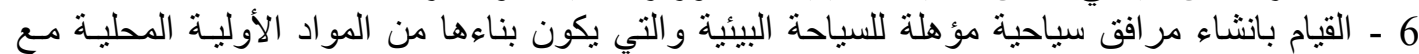

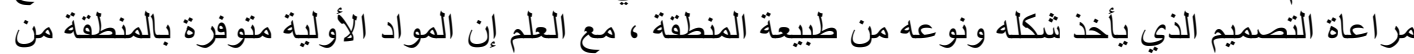

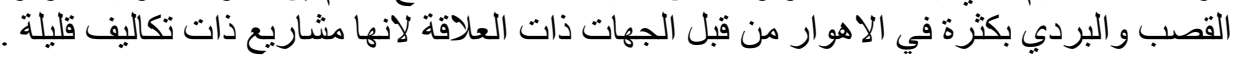

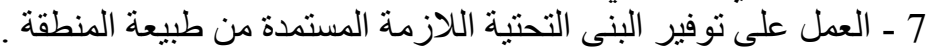

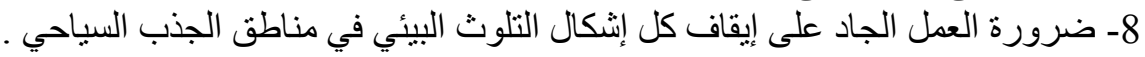

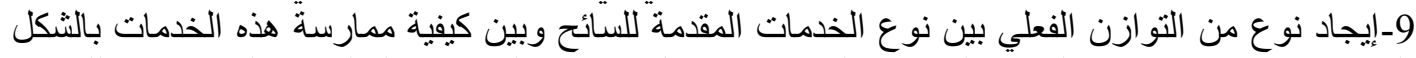

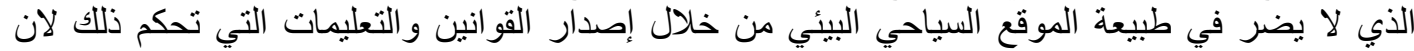
السياحة تعمل على شقين هما السياحة الداخلية لابناء البلد والسياحة الخارجية (السائح العربي و الاجنبي ) . 


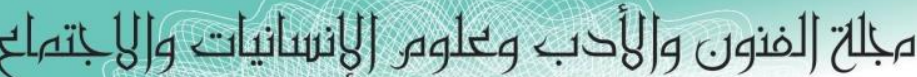

Journal of Arts, Literature, Humanities and Social Sciences

ISSN online: 2414 - 3383

ISSN print: 2616 - 3810

العدد (41) آب - أغسطس 2019

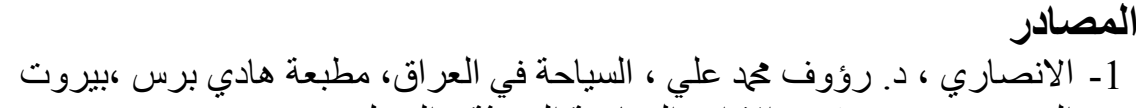

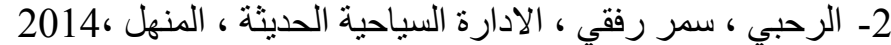

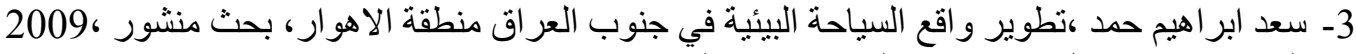

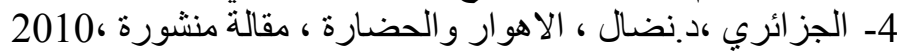

The Management Plans for the Natural Components. The Ahwar Southern Iraq : -5

The Refugeof Biodiversity and the Relict Landscape of the Mesopotamian Cities 2014

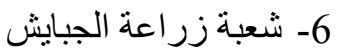

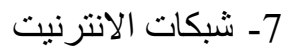

